\title{
Endarterectomy versus stenting for the prevention of periprocedural stroke or death in patients with symptomatic or asymptomatic carotid stenosis: a meta-analysis of 10 randomized trials
}

\author{
Wenqiang Xin, Shixue Yang, Qifeng Li, Xinyu Yang \\ Department of Neurosurgery, Tianjin Medical University General Hospital, Tianjin, China \\ Contributions: (I) Conception and design: X Yang, W Xin; (II) Administrative support: X Yang, W Xin; (III) Provision of study materials or patients: \\ W Xin, S Yang, X Yang; (IV) Collection and assembly of data: All authors; (V) Data analysis and interpretation: W Xin, S Yang; (VI) Manuscript \\ writing: All authors; (VII) Final approval of manuscript: All authors. \\ Correspondence to: Xinyu Yang, MD. Department of Neurosurgery, Tianjin Medical University General Hospital, Tianjin 300052, China. \\ Email: tumeduxinyu@yeah.net.
}

\begin{abstract}
Background: The incidence of stroke or death in carotid endarterectomy (CEA) versus carotid artery stenting (CAS) cannot be estimated accurately. We aimed to compare periprocedural stroke or death in patients with symptomatic or asymptomatic carotid artery stenosis (CS) treated with CEA versus CAS.

Methods: Ten randomized trials (with $\geq 100$ randomized patients per trial) compared the relative effectiveness of CAS and CEA for the prevention of stroke or death.

Results: In the symptomatic group during the periprocedural period, the results showed that the risk of death or any stroke [risk ratio (RR): $0.627 ; 95 \%$ CI: 0.497-0.792; $\mathrm{P}<0.001$ ] and the risk of any stroke (RR: 0.654; 95\% CI: 0.522-0.820; $\mathrm{P}<0.001)$ were significantly greater with CAS than with CEA. The difference in the risk of periprocedural stroke was mostly attributed to nondisabling stroke (RR: 0.407; 95\% CI: $0.264-$ 0.627; $\mathrm{P}<0.001$ ), which was driven especially by ipsilateral ischemic stroke (RR: 0.649; 95\% CI: 0.494-0.851; $\mathrm{P}=0.002$ ) and bradycardia or hypotension (RR: 0.105; 95\% CI: 0.051-0.217; P<0.001). However, we found that the CEA group had a higher rate of myocardial infarction than the CAS group (RR: 2.496; P=0.025). Meanwhile, ipsilateral stenosis $>70 \%$ increased the incidence of periprocedural death or stroke for postCEA patients (RR: $2.166,95 \%$ CI: 1.112 to $4.220, \mathrm{P}=0.023$ ), but no risk factors were identified for postCAS. Regarding the asymptomatic group, the results demonstrated that patients randomized to CEA had a significantly reduced risk of periprocedural stroke (RR: 0.518; 95\% CI: 0.281-0.954; P=0.035), which seems to be driven by periprocedural minor stroke (RR: 0.482; 95\% CI: 0.231-0.982; P=0.046).

Conclusions: Among patients with symptomatic CS, CEA was associated with reduced rates of periprocedural stroke and periprocedural nondisabling stroke. Among patients with asymptomatic CS, the rates of minor stroke and stroke in general were higher with stenting than with CEA. Based on the current data, CEA is more beneficial than CAS for 30-day stroke prevention.
\end{abstract}

Keywords: Carotid endarterectomy (CEA); carotid artery stenting (CAS); stroke prevention

Submitted Jun 10, 2020. Accepted for publication Oct 16, 2020.

doi: 10.21037/atm-20-4620

View this article at: http://dx.doi.org/10.21037/atm-20-4620

\section{Introduction}

Extracranial atherosclerotic carotid occlusive disease is generally regarded as a common significant cause of stroke (1). The prevalence of stroke in the adult population with carotid artery stenosis (CS) is up to $10-20 \%(2,3)$, usually leading to significant disability and fatality. Stroke is a complication of carotid revascularization that greatly influences the choice of surgical treatment in stroke 
prevention (4). Much research has been conducted over the past decades on applying endarterectomy or stents to treat CS $(2,5)$. Carotid endarterectomy (CEA) has proven highly effective in decreasing the incidence of stroke among patients with symptomatic or asymptomatic CS $(6,7)$; in addition, carotid artery stenting (CAS) is advocated as a viable alternative to CEA with several potential advantages (8). Outcomes after CAS among patients with symptomatic or asymptomatic CS were not inferior to those who received CEA in the prevention of stroke or death in a trial (9). However, consequences from several large trials in patients with symptomatic or asymptomatic CS have revealed a higher risk of stroke with CAS $(10,11)$. Furthermore, until the baseline differences in patient selection can be largely minimized and more evidence from large-scale randomized trials is available, the incidence of stroke or death between CEA and CAS cannot be estimated accurately. Therefore, we aimed to collect related data from randomized controlled trials (RCTs) and compare the periprocedural outcomes in patients with symptomatic or asymptomatic CS treated with CAS versus CEA to allow a comparison of the effectiveness of these two approaches. We present the following article in accordance with the PRISMA (Preferred Reporting Items for Systematic Reviews and Meta-analyses) reporting checklist (available at http://dx.doi.org/10.21037/atm-204620) (12).

\section{Methods}

\section{Literature and search strategy}

For the analysis, we searched publicly available electronic databases, including PubMed and Embase, from inception to May 2019 and retrieved research literature on all RCTs that compared CAS with CEA for patients with CS. We retrieved the following keywords, combined using with Boolean logic: "endarterectomy", "carotid artery stenting", and "carotid artery stenosis". The search strategy for trials comparing CAS to CEA is shown in Table S1. Beyond that, the research of the appraisal reference list was manually checked to determine other potential qualification trials. The process was iterated until no more articles could be obtained.

\section{Study selection}

The articles were incorporated into the present metaanalysis if the literature met the following criteria: (I) the RCT compared CEA with CAS for patients with asymptomatic and symptomatic CS; (II) the RCT randomized $\geq 100$ patients to reduce the potential effects of publication bias; and (III) one or more adequate data analyses of the outcomes could be conducted within 30 days. Non-English-language publications, case reports, comments, letters, editorials, protocols, guidelines, review papers, and animal studies were excluded.

\section{Endpoints and definitions}

Data on the baseline demographics, study design, and results were extracted from every included study. In the symptomatic group, the primary study endpoint measures were related to death (death, death or any stroke, death or disabling stroke, death or disabling ipsilateral stroke) in the first 30 days after the procedure. The secondary endpoint was a composite of any stroke, fatal stroke, disabling stroke, disabling ipsilateral stroke, ipsilateral ischemic stroke, nondisabling stroke, and intracerebral bleeding. The other outcomes of interest were encompassed by a composite endpoint of transient ischemic attacks (TIAs) and bradycardia or hypotension.

The composite endpoint of the asymptomatic group comprised death, death or any stroke, any stroke, ipsilateral stroke, major stroke, and minor stroke. The definitions of minor stroke and major stroke were associated with a new neurological deficit that increased National Institutes of Health Stroke Scale (NIHSS) scores or were completely resolved in 30 days. More details about the definitions of minor and major stroke are shown in Table S2.

The effects of female sex, ipsilateral stenosis $>90 \%$, and right stenosis after CAS on periprocedural death or stroke were examined for patients with symptomatic CS. Meanwhile, five risk factors (female sex, right stenosis, ipsilateral stenosis $>70 \%$, prior ipsilateral stroke, and contralateral CS defined as stenosis $>50 \%$ ) were accessed for asymptomatic patients. This study was unable to conduct a pooled landmark analysis for the risk factors for periprocedural death or stroke for asymptomatic CS due to inadequacies in the data reported in the published articles. The endpoint definitions applied in each study have been incorporated into Table S2, which provides further details.

\section{Data extraction}

Two of the reviewers extracted data from the included studies. The following essential information was recorded: 
first author's name, publication year, sample size, study design, outcomes and other relevant data. The extracted data (median, range, and the size of the trial) were input into the designed standardized table. When there were differences of opinion, another leading author was responsible for the final decision; this author contacted the authors of potentially relevant RCTs to clarify ambiguities on eligibility and to request relevant unpublished data. The endpoint definitions applied in each study were incorporated, and further details are provided in Table $\mathrm{S} 2$.

\section{Quality assessment}

The Cochrane Collaboration's tool was used to assess the risk of bias of each included study. Specifically, each study was evaluated for random sequence generation, allocation concealment, blinding of participants and personnel, blinding of outcome assessment, incomplete outcome data, selective reporting, and other sources of bias. For each bias domain, 3 independent reviewers provided a score of high, unclear, or low risk of bias. When there were differences of opinion, another leading author was involved until disagreements were resolved by consensus.

\section{Statistical analysis}

The intention-to-treat population was selected for analysis, and events within 1 month (30 days) were enrolled to preserve analysis homogeneity. The characteristics of every study were combined for an overall pooled analysis. Continuous variables are expressed as the mean $\pm \mathrm{SD}$ and were compared using the paired or unpaired Student's $t$-test as appropriate. Categorical variables are displayed as counts and percentages, which were compared using Fisher's exact test or the chi-square test. SPSS version 23.0 (IBM, Armonk, New York, USA) was used for these purposes. Furthermore, we used STATA version 11.0 (Stata Corporation, College Station, Texas, USA) for endpoint analyses. Heterogeneity across trials was identified were each outcome using $\mathrm{I}^{2}$ statistics (with $\mathrm{I}^{2}<25 \%$ being low and $\mathrm{I}^{2}>75 \%$ being high heterogeneity) and Cochran's $\mathrm{Q}$ (with $\mathrm{P}<0.1$ indicating significance). When $\mathrm{I}^{2}>25 \%$, we considered the data to have heterogeneity, and we conducted a meta-analysis using a random-effects model according to the Cochrane Handbook for Systematic Reviews of Interventions (version 5.1.0). Otherwise, a fixedeffects model was performed. All discontinuous various outcome risk differences (RDs) or risk ratios (RRs) with 95\% CIs were applied for the assessment.

\section{Results}

\section{Search results}

A total of 2,373 studies were identified as potentially relevant literature reports. A total of 910 reports were removed because of duplication. After the titles and abstracts were scanned, 1,415 reports were excluded according to the eligibility criteria. Twenty-five reports were eliminated after the full text was browsed. One study was obtained by the reference review. Ultimately, 10 trials were eligible for data extraction and meta-analysis. The search process and results are shown in Figure 1 and Table S3, respectively.

\section{Study and patient characteristics}

A total of 10 trials (14 articles) $(2,8,10,11,13-22)$ were involved in our study, including 9,527 participants. Of these 9,527 patients with CS, 6,757 were randomized to the symptomatic group, and 2,770 were randomized to the asymptomatic group. There were $7(10,11,13-15,17,22)$ and $2(8,16)$ RCTs with enrollment restricted to symptomatic and asymptomatic patients, respectively. In the symptomatic group, of these 6,757 patients, 3,399 were randomized to CAS and 3,358 were randomized to CEA. The average ages were from 66.4 to 70.0 years, the ratios of women varied between $27.6 \%$ and $35.9 \%$, and $\geq 89 \%$ of patients appeared with a CS of $\geq 70 \%$ in the 4 articles that showed this characteristic. Hyperlipidemia patients were more common in patients randomized to CEA. In the asymptomatic group, of these 2,770 patients, 1,751 were randomized to CAS and 1,019 were randomized to CEA. Current smokers were more common among patients randomized to CAS. A mean of $89.6 \%$ and $88.2 \%$ of enrolled patients in the CAS and CEA groups, respectively, had hypertension. A total of $35.1 \%$ and $34.1 \%$ of the included patients presented with diabetes mellitus. Only the CREST (2) trial included symptomatic and asymptomatic patients. The baseline characteristics of the study participants and additional study characteristics are presented in Table 1 and the Appendix 1, respectively. In each RCT, aspirin or clopidogrel was given before the operation, and these antiplatelet drugs were also given to patients after CEA or CAS in CREST (2), ACT I (8), EVA 3S (14), ICSS (11), and SPACE (13). The 

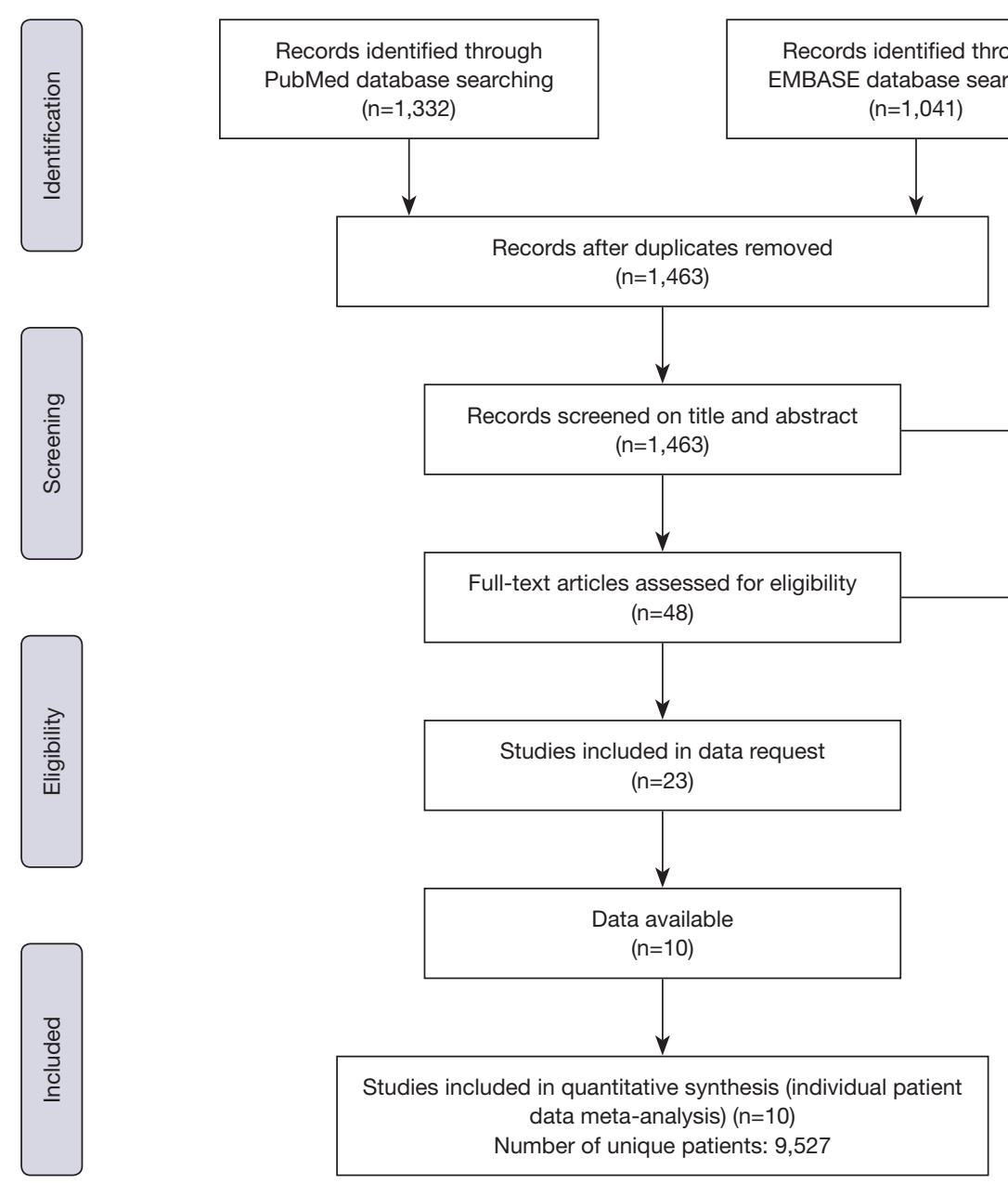

Figure 1 Flowchart of the study selection process.

types of stents differed among articles owing to advances in medicine, and the type of endarterectomy was decided by the operator according to the real need.

\section{Quality assessment}

Most of the included RCTs were high quality. Most of them showed a low risk of bias for random sequence generation, blinding of outcome assessment, incomplete outcome data, and selective reporting. However, significant performance bias was inevitable, as the researchers, laboratories, and patients were not blinded to the study arms. Two studies [Kentucky (17) and Wallstent (22)] shared high attrition bias owing to small samples, resulting in incomplete data. The results of the quality assessment of trials are provided in Table S4.

\section{Outcomes of patients with symptomatic CS}

During the periprocedural period, defined as the 30 days after CEA or CAS in most studies, a total of 8 articles $(2,10,11,13-15,17,22)$ reported data on the outcome of the risk of periprocedural death or any stroke. The results show that the risk of death or any stroke was significantly greater with CAS (RR: 0.627; 95\% CI: 0.497-0.792; $\mathrm{P}<0.001$, Figure 2). Similarly, five articles $(2,11,13,15,17)$ demonstrated the relationship of the risk of any stroke between the CEA and CAS groups (RR: 0.654; 95\% CI: $0.522-0.820 ; \mathrm{P}<0.001$, Figure $\mathrm{S} 1)$. However, the risk of periprocedural death was not significantly different between CEA and CAS ( $\mathrm{P}=0.267)$.

The risk of periprocedural nondisabling stroke was significantly lower with CEA (RR: 0.407; 95\% CI: $0.264-$ $0.627 ; \mathrm{P}<0.001$, Figure S2), which was mainly attributable 
Table 1 Baseline characteristics according to two interventions for patients with carotid stenosis in randomized trials, grouped by patient symptom

\begin{tabular}{|c|c|c|c|c|c|c|}
\hline Characteristics & \multicolumn{3}{|c|}{ Symptomatic } & \multicolumn{3}{|c|}{ Asymptomatic } \\
\hline Male & $2,325 / 3,346(69.5 \%)$ & 2,315/3,307 (70.0\%) & 0.646 & $1,090 / 1,751(62.3 \%)$ & $651 / 1,019(63.9 \%)$ & 0.390 \\
\hline \multicolumn{7}{|l|}{ Vascular risk factors } \\
\hline Hypertension & 2,426/3,292 (73.7\%) & 2,420/3,246 (74.6\%) & 0.229 & 1,569/1,751 (89.6\%) & $899 / 1,019(88.2 \%)$ & 0.260 \\
\hline Cholesterol & $252 / 565(44.6 \%)$ & 230/563 (40.9\%) & 0.203 & NA & NA & NA \\
\hline Hyperlipidemia & $1,036 / 1,521(68.1 \%)$ & $1,092 / 1,510(72.3 \%)$ & 0.011 & 1,569/1,751 (89.6\%) & $905 / 1,019(88.8 \%)$ & 0.515 \\
\hline \multicolumn{7}{|l|}{ Smoker } \\
\hline Ex-smoker & $408 / 853(47.8 \%)$ & $424 / 857$ (49.5\%) & 0.497 & $803 / 1,089(73.7 \%)$ & 259/364 (71.2\%) & 0.336 \\
\hline Coronary vascular disease & $537 / 1,927$ (27.9\%) & $570 / 1,877(30.4 \%)$ & 0.090 & $721 / 1,683(42.8 \%)$ & $430 / 951(45.2 \%)$ & 0.238 \\
\hline MI & 222/1,365 (16.3\%) & 230/1,369 (16.8\%) & 0.706 & NA & NA & NA \\
\hline AF & $69 / 1,104(6.25 \%)$ & $71 / 1,110(6.4 \%)$ & 0.887 & NA & NA & NA \\
\hline Peripheral vascular disease & 236/1,365 (17.3\%) & 217/1,369 (15.9\%) & 0.312 & $391 / 1,089(35.9 \%)$ & $124 / 364(34.1 \%)$ & 0.526 \\
\hline CABG & $221 / 1,521(14.5 \%)$ & $226 / 1,510(15.0 \%)$ & 0.734 & $140 / 594(23.6 \%)$ & $156 / 587(26.6 \%)$ & 0.233 \\
\hline \multicolumn{7}{|l|}{ Brain imaging } \\
\hline No infraction & $426 / 1,206(35.3 \%)$ & $435 / 1,173(37.1 \%)$ & 0.372 & NA & NA & NA \\
\hline Embolic stroke & 495/1,206 (41.0\%) & $464 / 1,173(40.0 \%)$ & 0.459 & NA & NA & NA \\
\hline Retinal infraction & $11 / 512(2.1 \%)$ & $8 / 512(1.6 \%)$ & 0.487 & NA & NA & NA \\
\hline TIA & $578 / 1,771(32.6 \%)$ & $573 / 1,736(33.0 \%)$ & 0.816 & NA & NA & NA \\
\hline Multiple & 93/1,206 (7.7\%) & $111 / 1,173(9.5 \%)$ & 0.127 & NA & NA & NA \\
\hline Others & $63 / 1,467$ (4.3\%) & $53 / 1,432(3.7 \%)$ & 0.377 & NA & NA & NA \\
\hline \multicolumn{7}{|l|}{ Degree of symptomatic CS } \\
\hline $50-59 \%$ & $97 / 599$ (16.2\%) & 96/584 (16.4\%) & 0.909 & NA & NA & NA \\
\hline $60-69 \%$ & $274 / 1,457$ (18.8\%) & $272 / 1,426(19.1 \%)$ & 0.854 & NA & NA & NA \\
\hline $70-79 \%$ & $150 / 1,457(10.3 \%)$ & $152 / 1,426(10.7 \%)$ & 0.750 & $551 / 594$ (92.8\%) & $539 / 587$ (91.8\%) & 0.546 \\
\hline $80-89 \%$ & $504 / 1,457$ (34.6\%) & 484/1,426 (33.9\%) & 0.713 & NA & NA & NA \\
\hline $90-99 \%$ & $216 / 850(25.4 \%)$ & 197/837 (23.5\%) & 0.370 & NA & NA & NA \\
\hline
\end{tabular}

Table 1 (continued) 
Table 1 (continued)

\begin{tabular}{|c|c|c|c|c|c|c|}
\hline Characteristics & \multicolumn{3}{|c|}{ Symptomatic } & \multicolumn{3}{|c|}{ Asymptomatic } \\
\hline $100 \%$ & $4 / 1,456(0.27 \%)$ & $1 / 1,437(0.07 \%)$ & 0.184 & NA & NA & NA \\
\hline Unknown & $2 / 2,310(0.09 \%)$ & $7 / 2,283(0.31)$ & 0.092 & NA & NA & NA \\
\hline Contralateral CS $70-100 \%$ & $336 / 2,978(11.3 \%)$ & $341 / 2,936(11.6 \%)$ & 0.689 & NA & NA & NA \\
\hline 0 or 1 & $1,184 / 1,467$ (80.7\%) & 1,162/1,432 (81.1\%) & 0.765 & NA & NA & NA \\
\hline 2 or 3 & $282 / 1,467(19.2 \%)$ & $270 / 1,432(18.9 \%)$ & 0.801 & NA & NA & NA \\
\hline Unknown & $1 / 1,467(0.07 \%)$ & $0 / 1,432(0 \%)$ & 1.0 & NA & NA & NA \\
\hline \multicolumn{7}{|l|}{ Concomitant medication } \\
\hline Lipid-lowering drugs & $1,238 / 2,320(53.4 \%)$ & $1,264 / 2,289(55.2 \%)$ & 0.205 & NA & NA & NA \\
\hline Antihypertension & $766 / 1,114(68.8 \%)$ & $772 / 1,116(69.2 \%)$ & 0.832 & NA & NA & NA \\
\hline Antidiabetic & $53 / 261(20.3 \%)$ & $64 / 259(24.7 \%)$ & 0.229 & NA & NA & NA \\
\hline
\end{tabular}

CEA, carotid endarterectomy; CAS, carotid artery stenting; NA, not available; CS, carotid stenosis; MRS, MRS, modified Rankin scale; TIA, transient ischemic attacks; MI, myocardial Infarction; CABG, coronary artery bypass grafting.

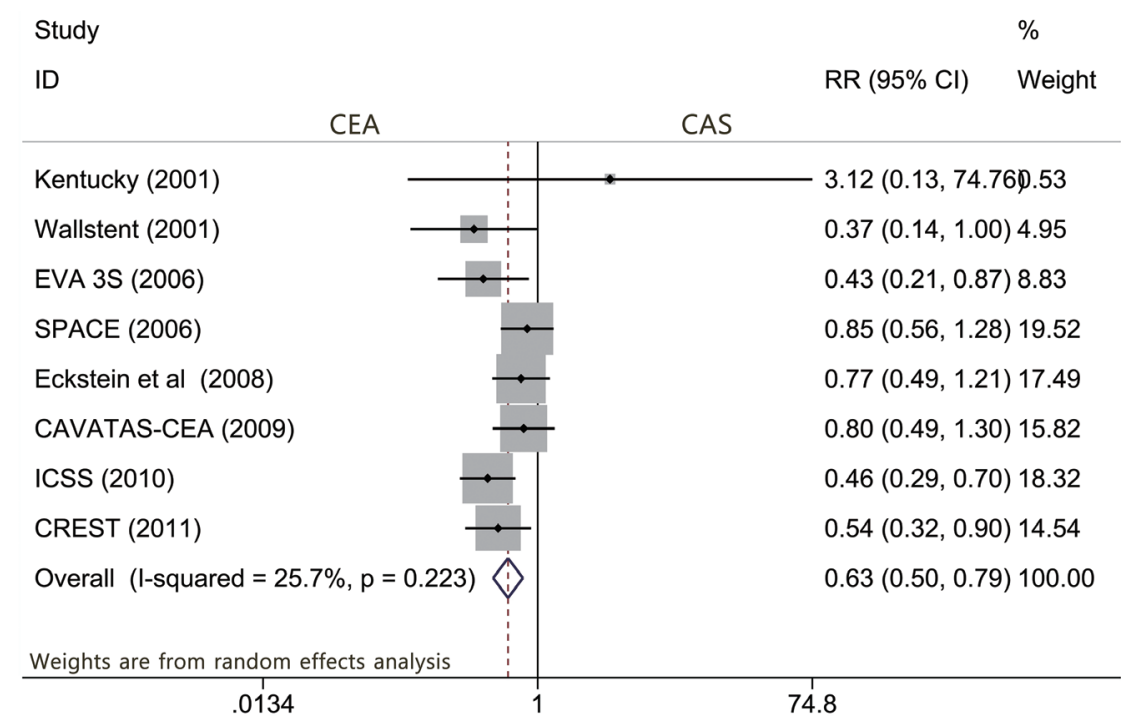

Figure 2 Forest plot for the assessment of death or any stroke.

to ipsilateral ischemic stroke (RR: 0.649; 95\% CI: $0.494-$ $0.851 ; \mathrm{P}=0.002$, Figure $\mathrm{S} 3$ ) and periprocedural bradycardia or hypotension (RR: 0.105; 95\% CI: 0.051-0.217; $\mathrm{P}<0.001$, Figure S4). Associated periprocedural ipsilateral intracerebral bleeding $(\mathrm{P}=0.092)$ and TIA $(\mathrm{P}=0.135)$ were not significantly different between CEA and CAS.

However, we found that the CEA group had a higher rate of myocardial infarction than the CAS group (RR: 2.496; $\mathrm{P}=0.025$ ). Furthermore, patients undergoing CAS experienced a similar associated fatal stroke rate as the CEA 
group $(\mathrm{P}=0.078)$. No significant difference was observed in periprocedural death or disabling stroke $(\mathrm{P}=0.133)$, death or disabling ipsilateral stroke $(\mathrm{P}=0.117)$, disabling ipsilateral stroke $(\mathrm{P}=0.067)$, and disabling stroke $(\mathrm{P}=0.700)$, which was also associated with significant heterogeneity between the two groups. Additional details are available in Table 2.

\section{Outcomes of patients with asymptomatic CS}

The results of our meta-analysis of the 3 articles $(2,8,16)$ providing perioperative events in asymptomatic patients demonstrated that patients randomized to CEA were associated with a statistically lower risk of periprocedural stroke than were those randomized to CAS (RR: 0.518; 95\% CI: 0.281-0.954; $\mathrm{P}=0.035$, Figure 3). The results of the pooled literature similarly revealed increased risks of periprocedural minor stroke after CAS (RR: 0.482; 95\% CI: 0.236-0.986; $\mathrm{P}=0.046$, Figure S5). However, the results were inconclusive regarding the risk of periprocedural death $(\mathrm{P}=0.637)$, death or any stroke $(\mathrm{P}=0.051)$, ipsilateral stroke $(\mathrm{P}=0.273)$, myocardial infarction $(\mathrm{P}=0.191)$, and major stroke $(\mathrm{P}=0.524)$. No significant heterogeneity was found in these outcomes by pooling the included trials. Detailed outcome reporting is available in Table 2.

\section{Risk factors for periprocedural death or stroke for symptomatic CS}

We extracted the female values from two included articles. The results of the meta-analysis showed that no significant differences were observed for females with respect to periprocedural death or stroke rate of symptomatic CS following CAS operation $(\mathrm{P}=0.819)$. The results of the pooled literature similarly revealed that side of right stenosis $(\mathrm{P}=0.634)$ and stenosis $>90 \%(\mathrm{P}=0.880)$ had no effect on periprocedural death or stroke after CAS with no heterogeneity $\left(\mathrm{I}^{2}=0 \%\right)$. The meta-analysis results of risk factors for periprocedural death or stroke for those patients with symptomatic stenosis undergoing CAS are shown in Table 2.

Similar to the results described above, female sex $(\mathrm{P}=0.476)$, side of right stenosis $(\mathrm{P}=0.252)$, contralateral stenosis $(\mathrm{P}=0.091)$, and prior ipsilateral stroke $(\mathrm{P}=0.084)$ had no effect on periprocedural death or stroke after CEA. Two publications $(20,21)$ focused on the effect of stenosis $>70 \%$ after CEA on periprocedural death or stroke. There was no heterogeneity in the statistical results of the pooled literature $\left(\mathrm{I}^{2}=0 \%, \mathrm{P}=0.553\right)$. The result of the fixed-effects model showed that patients with ipsilateral stenosis $>70 \%$ had an increased incidence of periprocedural death or stroke $(\mathrm{RR}=2.166,95 \% \mathrm{CI}: 1.112$ to $4.220, \mathrm{P}=0.023$, Figure 4). Detailed outcome reporting is available in Table 2.

\section{Discussion}

The purpose of our study was to examine the safety and efficacy of stenting compared with endarterectomy in patients with carotid stenosis, with a particular focus on short-term outcomes. Our analysis, including data from 6,757 symptomatic patients and 2,770 asymptomatic patients across $10 \mathrm{RCTs}$, revealed that the aggregate efficacy outcome of stroke, any stroke or death during the periprocedural 30 days did differ between CAS and CEA. The study designs and patient populations were very similar among the included trials, which is the major advantage of the present meta-analysis (4).

This meta-analysis of symptomatic patient data indicates that the short-dated risk of death or any stroke was much higher after CAS than after CEA, which is consistent with the findings of a previous study (4). The estimated rates of death or any stroke were $8.20 \%$ at the periprocedural period in the CAS group compared with $5.04 \%$ in the CEA group. In addition, our results demonstrated that CAS had higher risks of nondisabling stroke than CEA did during the shortterm periprocedural 30 days. The analysis of the CREST trial revealed that periprocedural minor stroke had negative effects on patients' physical and mental health components on the SF-36 (36-Item Short Form Health Survey) qualityof-life scale measured at 1 year (23). Consequently, the excess of minor nondisabling strokes was probably responsible for the difference in periprocedural stroke. CAS was a less invasive therapy than CEA, avoided the risk of surgical complications and could treat surgically inaccessible lesions that were distant from the carotid bifurcation in the symptomatic group (24). Furthermore, compared with CAS, CEA also reduced the incidence of ipsilateral ischemic stroke and complications of bradycardia or hypotension. Another possibility is that hemodynamic instability, such as bradycardia or hypotension, as well as altered flow patterns, may explain, to some extent, the difference in stroke risk between CAS and CEA (25). Meanwhile, there seemed to be no significant difference in other outcome measures.

In this analysis of 2,770 patients with asymptomatic carotid stenosis treated with CEA or CAS, we found that CAS was associated with a nearly 2 -fold greater odds of periprocedural stroke (1.37\% vs. $2.68 \%$ ) or minor stroke 
Table 2 Results of the meta-analysis

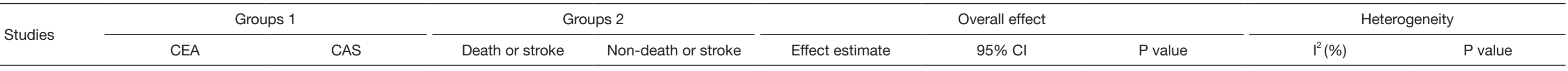

Outcome

Death or any stroke

Any stroke

Death

Non-disabling stroke

Ipsilateral ischemic stroke

Bradycardia or hypotension

Ipsilateral intracerebral bleeding

TIA

Fatal stroke

Death or disabling stroke

Death or disabling ipsilateral stroke

Disabling ipsilateral stroke

Disabling stroke

Myocardial Infarction

Meta-analysis results of asymptomatic stenosis

Death

Death or any stroke

Any stroke

Ipsilateral stroke

Minor stroke

Myocardial Infarction

Risk factors of periprocedural death or stroke for those

patients with symptomatic stenosis undergoing CAS

Female

Side of right

Stenosis $>90 \%$

Risk factors of periprocedural death or stroke for those

(

Female

Side of right

Stenosis $>70 \%$

Contralateral stenosis

Prior ipsilateral stroke

CEA, carotid endarterectomy: CAS, carotid artery stenting: $\mathrm{Cl}$, confidence interval: TIA, transient ischemic attacks.

$\begin{array}{ll}4.8 \%, 160 / 3,332 & 7.7 \%, 260 / 3,398 \\ 4.3 \%, 116 / 2,672 & 6.7 \%, 181 / 2,721 \\ 3.4 \%, 120 / 3,493 & 5.4 \%, 193 / 3,549 \\ 2.1 \%, 28 / 1,333 & 5.1 \%, 69 / 1,340 \\ 4.1 \%, 81 / 1,968 & 6.4 \%, 127 / 2,000 \\ 0.4 \%, 7 / 1,721 & 4.6 \%, 77 / 1,659 \\ 0.8 \%, 9 / 1,147 & 0.3 \%, 3 / 1,172 \\ 0.6 \%, 2 / 310 & 2.2 \%, 7 / 314 \\ 1.4 \%, 23 / 1,643 & 2.2 \%, 37 / 1,662 \\ 2.8 \%, 37 / 1,333 & 3.8 \%, 51 / 1,340 \\ 3.4 \%, 39 / 1,147 & 4.7 \%, 55 / 1,172 \\ 2.7 \%, 31 / 1,147 & 4.1 \%, 48 / 1,172 \\ 2.0 \%, 26 / 1,333 & 2.2 \%, 30 / 1,340 \\ 1.29 \%, 22 / 1,709 & 0.5 \%, 8 / 1,752 \\ & \\ 0.1 \%, 1 / 1,019 & 0.06 \%, 1 / 1,751 \\ 1.5 \%, 15 / 1,019 & 2.7 \%, 48 / 1,751 \\ 1.4 \%, 14 / 1,019 & 2.7 \%, 47 / 1,751 \\ 1.4 \%, 6 / 432 & 2.3 \%, 27 / 1,157 \\ 0.3 \%, 3 / 951 & 0.5 \%, 8 / 1,683 \\ 1.1 \%, 10 / 951 & 2.3 \%, 38 / 1,683 \\ 1.6 \%, 16 / 1,004 & 0.69 \%, 12 / 1,751\end{array}$

$6.8 \%, 46 / 676$

$8.1 \%, 33 / 406$

$7.5 \%, 14 / 186$

$6.0 \%, 36 / 599$

$7.4 \%, 34 / 462$

$5.6 \%, 49 / 880$

$4.3 \%, 29 / 671$

$5.5 \%, 61 / 1,107$

$5.9 \%, 19 / 322$

$7.3 \%, 26 / 355$
$3.8 \%, 43 / 1,120$

$5.7 \%, 42 / 739$

$3.35 \%, 10 / 303$

$4.7 \%, 51 / 1,082$

$3.5 \%, 45 / 1,303$
RR, 0.627

RR, 0.654

$\mathrm{RR}, 0.726$

RR, 0.407

RR, 0.649

RR, 0.105

RR, 3.064

RR, 0.338

RR, 0.631

RR, 0.727

RR, 0.725

RR, 0.660

RR, 0.854

RR, 2.496

RD, 0.001

RR, 0.556

RR, 0.518

RR, 0.606

RR, 0.640

RR, 0.482

$\mathrm{RD}, 0.005$

RR, 1.074

RR, 1.118

RR, 0.957

RR, 1.231

RR, 0.764

RR, 2.166

RR, 1.582

RR, 2.035

\subsection{7-0.792}

$0.522-0.820$

0.413-1.277

0.264-0.627

0.494-0.851

$0.051-0.217$

$0.832-11.283$

0.081-1.402

0.366-1.055

0.480-1.102

0.485-1.083

0.423-1.029

0.382-1.907

1.119-5.566

$-0.003-0.004$

0.309-1.002

0.281-0.954

$0.247-1.483$

$0.162-2.529$

0.236-0.986

$-0.003-0.013$

$<0.001$

25.7

$<0.001$

0.267

$<0.001$

0.002

$<0.001$

0.092
0.135

0.078

0.133

0.117

0.067

0.700
0.025

17.4

0.304

0.416

0.340
0.297

0.408

0.504

0.987

0.474

0.554

0.578

0.657

0.167

0.557

0.637

0.051

0.035

0.273

0.046
0.191

0.584-1.973

$0.706-1.773$

$0.542-1.690$

0.819

0.634

0.880

$\begin{array}{llrl}0.696-2.177 & 0.476 & 41.6 & 0.181 \\ 0.482-1.211 & 0.252 & 0.0 & 0.859 \\ 1.112-4.220 & 0.023 & 0.0 & 0.553 \\ 0.930-2.690 & 0.091 & 0.0 & 0.349 \\ 0.910-4.551 & 0.084 & 53.3 & 0.143\end{array}$




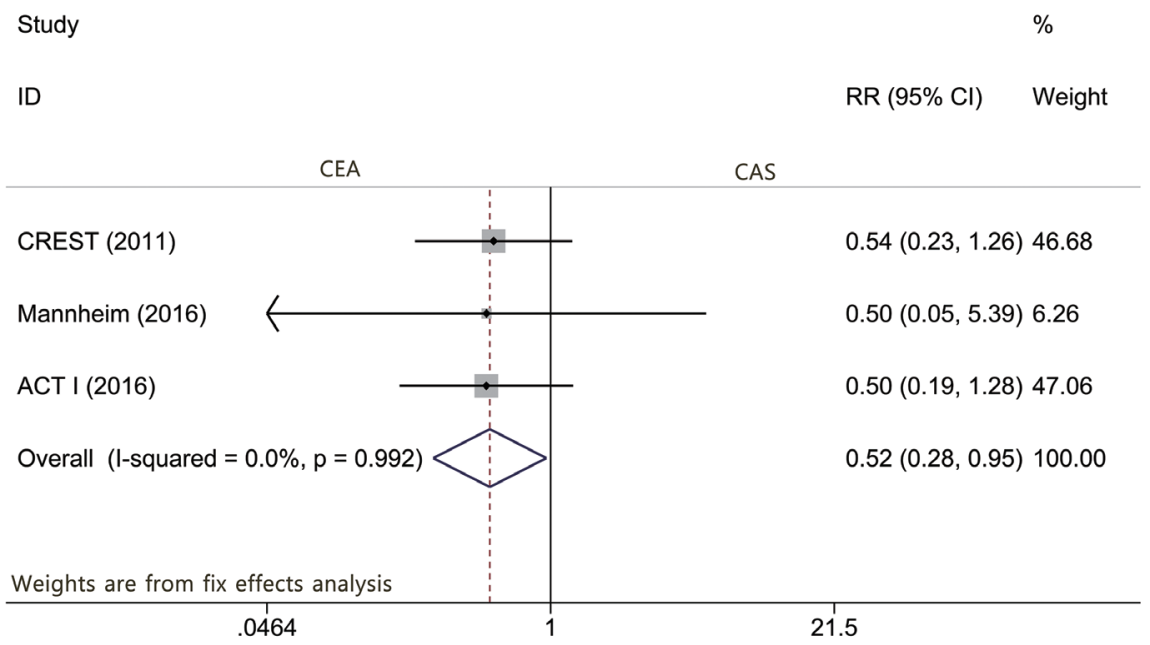

Figure 3 Forest plot for the assessment of any periprocedural stroke.

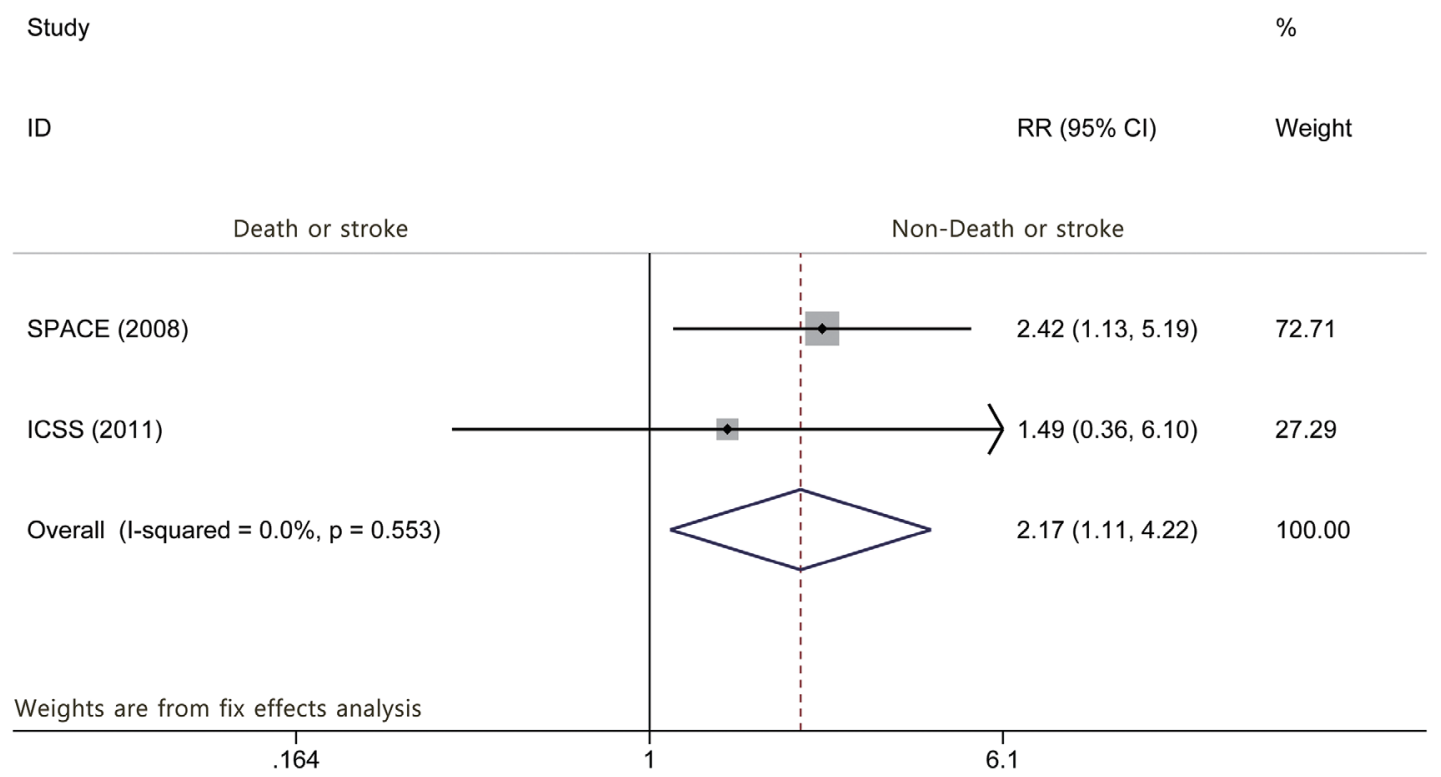

Figure 4 Forest plot of the relationship between ipsilateral stenosis $>70 \%$ and the rates of death or stroke after CEA. CEA, carotid endarterectomy.

(1.05\% vs. 2.26\%) than CEA. This argument was in keeping with a previous study that even after adjustment for baseline differences in patient characteristics for asymptomatic carotid stenosis, the risk of postoperative stroke was substantially higher when the patients were treated with CAS than when they were treated with CEA (26). To our knowledge, carotid revascularization has two major methods: CEA contributes to plaque passivation by removing the offending plaque and its components, whereas CAS contributes to plaque passivation by stent reendothelialization, which essentially segregates the contents of the plaque from the arterial lumen (27). Guidelines on acceptable operative risk from the Stroke Council of the American Heart Association recommend that the combined risk of stroke and death resulting from CEA should be no more than 3\% for asymptomatic patients and $6 \%$ for symptomatic patients. In asymptomatic carotid stenosis patients, CAS is widely accepted as an efficient 
treatment that avoids wound complications and general anesthesia.

Increased knowledge of risk factors could improve the assignment of patients to these procedures and reduce overall risk. In addition, except for patients with stenosis $>70 \%$, which could increase the incidence of periprocedural death or stroke, our results demonstrated no significant risk factors for periprocedural death or stroke for symptomatic carotid stenosis. Furthermore, the association between the degree of stenosis (>70\%) and the risk of death or stroke included the CEA group but not the CAS group. However, CEA is associated with a higher-than-average perioperative risk in patients with contralateral occlusive internal carotid artery (28), which means that more data from symptomatic patients are needed. Although the underlying mechanism was unclear, several studies reported that the smaller vessel lumen diameter in women increased the technical difficulty of CAS and seemed to increase the risk accordingly $(18,21)$, but in this study, we did not observe a significant difference in risk between females and males.

Although the results suggest that CEA is more beneficial than CAS for stroke prevention, many guidelines recommend that therapy decisions for asymptomatic patients with high or moderate risks be based on an integral evaluation, including their expected life span, comorbid conditions and other individualized aspects (29). It is reasonable to use CAS for patients with high surgical risk for surgery. Prophylactic CAS might be recommended for patients with moderate risk. Several published metaanalyses comparing CAS with CEA in high-risk populations also revealed that patient characteristics (such as restenotic lesions and age) and procedural factors (such as stent type and patch type) might affect the outcomes of carotid revascularization (30). The results therefore may help to establish further clinical recommendations. Mid- to longterm effectiveness is the key factor for decision making.

\section{Study limitations}

The present study has several potential limitations. First, the current study merely compares 30-day clinical outcomes relevant to death or stroke with the two interventions due to relatively little data on death or stroke during the same long-term follow-up period. Second, some heterogeneity was found among the included trials in the study protocols, patient characteristics, definitions of clinical endpoints, stent types used, and variation in the use of embolicprotection devices (EPD). We were unable to perform a subgroup analysis based on device type or patient characteristics. Therefore, we provide a supplementary table with the details of the CEA and CAS techniques used and the intervention of antiplatelet therapy in Table S5. Third, the main inclusion and exclusion criteria of trials and participant characteristics were different in the included studies, potentially causing bias. For example, for the use of antiplatelets after intervention, only patients in trials of CREST (2), ACT I (8), EVA 3S (14), ICSS (11), and SPACE (13) were given aspirin or clopidogrel. Fourth, stroke definitions were not discussed in three studies. Finally, although this text revealed that CEA was more beneficial than CAS for 30-day stroke prevention, a direct comparison between CEA and CAS for symptomatic or asymptomatic CS could not conclude that CEA was safer and more efficient for CS patients, and more powerful and better-designed studies are necessary to reach a firmer conclusion.

\section{Conclusions}

Among patients with symptomatic CS, lower rates of periprocedural stroke and periprocedural nondisabling stroke were associated with CEA than with stenting. Among patients with asymptomatic CS, stenting had significantly higher rates of minor stroke and stroke in general than CEA. Based on the current data, CEA is more beneficial than CAS for 30-day stroke prevention.

\section{Acknowledgments}

Funding: Our work was supported by funding from the National Natural Science Foundation of China (No. $81570507, \mathrm{XY})$.

\section{Footnote}

Reporting Checklist: The authors have completed the PRISMA reporting checklist. Available at http://dx.doi. org/10.21037/atm-20-4620

Peer Review File: Available at http://dx.doi.org/10.21037/ atm-20-4620

Conflicts of Interest: All authors have completed the ICMJE uniform disclosure form (available at http://dx.doi. org/10.21037/atm-20-4620). The authors have no conflicts of interest to declare. 
Ethical Statement: The authors are accountable for all aspects of the work in ensuring that questions related to the accuracy or integrity of any part of the work are appropriately investigated and resolved. All analyses were based on previously published studies in this meta-analysis; thus, no ethical approval or patient consent was required.

Open Access Statement: This is an Open Access article distributed in accordance with the Creative Commons Attribution-NonCommercial-NoDerivs 4.0 International License (CC BY-NC-ND 4.0), which permits the noncommercial replication and distribution of the article with the strict proviso that no changes or edits are made and the original work is properly cited (including links to both the formal publication through the relevant DOI and the license). See: https://creativecommons.org/licenses/by-nc-nd/4.0/.

\section{References}

1. Barrett KM, Brott TG. Stroke Caused by Extracranial Disease. Circ Res 2017;120:496-501.

2. Silver FL, Mackey A, Clark WM, et al. Safety of stenting and endarterectomy by symptomatic status in the Carotid Revascularization Endarterectomy Versus Stenting Trial (CREST). Stroke 2011;42:675-80.

3. Lovett JK, Coull AJ, Rothwell PM. Early risk of recurrence by subtype of ischemic stroke in populationbased incidence studies. Neurology 2004;62:569-73.

4. Bonati LH, Dobson J, Algra A, et al. Short-term outcome after stenting versus endarterectomy for symptomatic carotid stenosis: a preplanned meta-analysis of individual patient data. Lancet 2010;376:1062-73.

5. Moresoli P, Habib B, Reynier P, et al. Carotid Stenting Versus Endarterectomy for Asymptomatic Carotid Artery Stenosis: A Systematic Review and Meta-Analysis. Stroke 2017;48:2150-7.

6. Gurm HS, Yadav JS, Fayad P, et al. Long-term results of carotid stenting versus endarterectomy in high-risk patients. N Engl J Med 2008;358:1572-9.

7. Brott TG, Howard G, Roubin GS, et al. Long-Term Results of Stenting versus Endarterectomy for CarotidArtery Stenosis. N Engl J Med 2016;374:1021-31.

8. Rosenfield K, Matsumura JS, Chaturvedi S, et al. Randomized Trial of Stent versus Surgery for Asymptomatic Carotid Stenosis. N Engl J Med 2016;374:1011-20.

9. Yadav JS, Wholey MH, Kuntz RE, et al. Protected carotidartery stenting versus endarterectomy in high-risk patients.
N Engl J Med 2004;351:1493-501.

10. Ederle J, Bonati LH, Dobson J, et al. Endovascular treatment with angioplasty or stenting versus endarterectomy in patients with carotid artery stenosis in the Carotid and Vertebral Artery Transluminal Angioplasty Study (CAVATAS): long-term follow-up of a randomised trial. Lancet Neurol 2009;8:898-907.

11. Ederle J, Dobson J, Featherstone RL, et al. Carotid artery stenting compared with endarterectomy in patients with symptomatic carotid stenosis (International Carotid Stenting Study): an interim analysis of a randomised controlled trial. Lancet 2010;375:985-97.

12. Liberati A, Altman DG, Tetzlaff J, et al. The PRISMA statement for reporting systematic reviews and metaanalyses of studies that evaluate health care interventions: explanation and elaboration. Ann Intern Med 2009; 151:W65-94.

13. Ringleb PA, Allenberg J, Brückmann H, et al. 30 day results from the SPACE trial of stent-protected angioplasty versus carotid endarterectomy in symptomatic patients: a randomised non-inferiority trial. Lancet 2006;368:1239-47.

14. Mas JL, Chatellier G, Beyssen B, et al. Endarterectomy versus stenting in patients with symptomatic severe carotid stenosis. N Engl J Med 2006;355:1660-71.

15. Eckstein HH, Ringleb P, Allenberg JR, et al. Results of the Stent-Protected Angioplasty versus Carotid Endarterectomy (SPACE) study to treat symptomatic stenoses at 2 years: a multinational, prospective, randomised trial. Lancet Neurol 2008;7:893-902.

16. Mannheim D, Karmeli R. A prospective randomized trial comparing endarterectomy to stenting in severe asymptomatic carotid stenosis. J Cardiovasc Surg (Torino) 2017;58:814-7.

17. Brooks WH, McClure RR, Jones MR, et al. Carotid angioplasty and stenting versus carotid endarterectomy: randomized trial in a community hospital. J Am Coll Cardiol 2001;38:1589-95.

18. Howard VJ, Lutsep HL, Mackey A, et al. Influence of sex on outcomes of stenting versus endarterectomy: a subgroup analysis of the Carotid Revascularization Endarterectomy versus Stenting Trial (CREST). Lancet Neurol 2011;10:530-7.

19. Naggara O, Touzé E, Beyssen B, et al. Anatomical and technical factors associated with stroke or death during carotid angioplasty and stenting: results from the endarterectomy versus angioplasty in patients with symptomatic severe carotid stenosis (EVA-3S) trial and systematic review. Stroke 2011;42:380-8. 


\section{Page 12 of 12}

20. Doig D, Turner EL, Dobson J, et al. Risk Factors For Stroke, Myocardial Infarction, or Death Following Carotid Endarterectomy: Results From the International Carotid Stenting Study. Eur J Vasc Endovasc Surg 2015;50:688-94.

21. Stingele R, Berger J, Alfke K, et al. Clinical and angiographic risk factors for stroke and death within 30 days after carotid endarterectomy and stent-protected angioplasty: a subanalysis of the SPACE study. Lancet Neurol 2008;7:216-22.

22. Alberts MJ. Results of a multicenter prospective randomized trial of carotid artery stenting vs. carotid endarterectomy. Stroke 2001;32:325.

23. Sardar P, Chatterjee S, Aronow HD, et al. Carotid Artery Stenting Versus Endarterectomy for Stroke Prevention: A Meta-Analysis of Clinical Trials. J Am Coll Cardiol 2017;69:2266-75.

24. Mathur A, Roubin GS, Iyer SS, et al. Predictors of stroke complicating carotid artery stenting. Circulation 1998;97:1239-45.

Cite this article as: Xin W, Yang S, Li Q, Yang X. Endarterectomy versus stenting for the prevention of periprocedural stroke or death in patients with symptomatic or asymptomatic carotid stenosis: a meta-analysis of 10 randomized trials. Ann Transl Med 2021;9(3):256. doi: 10.21037/ atm-20-4620

\section{Xin et al. Endarterectomy versus stenting for stroke prevention}

25. Cassot F, Vergeur V, Bossuet P, et al. Effects of anterior communicating artery diameter on cerebral hemodynamics in internal carotid artery disease. A model study. Circulation 1995;92:3122-31.

26. Risk of stroke in the distribution of an asymptomatic carotid artery. The European Carotid Surgery Trialists Collaborative Group. Lancet 1995;345:209-12.

27. Safian RD. Asymptomatic Carotid Artery Stenosis: Revascularization. Prog Cardiovasc Dis 2017;59:591-600.

28. Rothwell PM, Eliasziw M, Gutnikov SA, et al. Endarterectomy for symptomatic carotid stenosis in relation to clinical subgroups and timing of surgery. Lancet 2004;363:915-24.

29. White CJ. Carotid artery stenting. J Am Coll Cardiol 2014;64:722-31.

30. Meershoek AJA, de Vries EE, Veen D, et al. Meta-analysis of the outcomes of treatment of internal carotid artery near occlusion. Br J Surg 2019;106:665-71. 
Table S1 Search strategy for trials comparing CAS to CEA

Carotid stenosis OR Carotid artery stenosis OR Carotid disease OR Carotid artery disease

AND

CAS OR Carotid artery stenting OR Carotid angioplasty OR Carotid stenting

AND

CEA OR Carotid endarterectomy OR Endarterectomy OR Carotid surgery OR Carotid revascularization

AND

Symptomatic or Asymptomatic

AND

Randomized controlled trial OR trial OR Randomized OR Groups OR Randomly OR Controlled clinical trial NOT Animals CEA, carotid endarterectomy; CAS, carotid artery stenting.

Table S2 Definitions of major stroke, minor stroke, disabling stroke, nondisabling stroke, ipsilateral stroke, and fatal stroke in the involved trials

\begin{tabular}{ll}
\hline Trials and year & The stroke was divided into minor and major stroke. \\
ACT I 2016 & The major stroke must contain one or more of the \\
listed items: & (1) The score of National Institute of Health stroke \\
scale (NIHSS) improved by at least 4 points than \\
before stroke. \\
(2) The score of modified Rankin scale (MRS) \\
improved by at least 2 points than before the stroke. \\
(3) The score of MRS was 5 or more caused by the \\
stroke. \\
The score must last 30 minutes.
\end{tabular}

CREST 2010 and 2016 The stroke was divided into minor and major stroke. Major stroke: the score of NIHSS was 9 or more within 3 months.

EVA-3S 2006

ICSS 2010 and 2015

SPACE 2006

CAVATAS-CEA 2009

Eckstein et al. 2008

Kentucky 2001

Wallstent 2001

Mannheim et al. 2016

The symptoms of stroke lasted at least 7 days. It was divided into disabling stroke, nondisabling stroke.

The stroke was divided into the disabling, nondisabling and stroke fatal stroke.

Fatal stroke: A patient suffered a rapidly developing syndrome, which caused by focal disturbance of cerebral function lasting at least 24 hours. Or, the patient died within 30 days of the stroke, and no other cause of vascular stroke was found to be accidental.

The stroke was divided into the ipsilateral stroke and disabling ipsilateral stroke.

Ipsilateral stroke: A patient suffered an ipsilateral stroke or intracerebral bleeding or both, and the symptom lasted at least $24 \mathrm{~h}$.

The strokes were divided into disabling, nondisabling, fatal stroke and TIA.

Disabling stroke: A patient suffered a rapidly developing syndrome, which caused by focal disturbance of cerebral function lasting at least 24 hours. And the patient needed help from others for at least one month due to the stroke. Fatal stroke: patient had rapidly developing syndrome, which caused by focal disturbance of cerebral function lasting at least 24 hours. Or, the patient died within 30 days of the stroke, and no other cause of vascular stroke was found to be accidental.

The stroke was divided into the ipsilateral stroke and any ipsilateral stroke.

Ipsilateral stroke: the cerebral infarction and/or cerebral bleeding.

Not Available.

Not Available.

Not Available.

CEA, carotid endarterectomy; CAS, carotid artery stenting; NIHSS, National Institute of Health stroke scale; MRS, modified Rankin scale; CREST, carotid revascularization endarterectomy versus stenting trial; SPACE, Stent-Protected Angioplasty versus Carotid Endarterectomy; EVA-3S, Endarterectomy versus Angioplasty in Patients with Symptomatic Severe Carotid Stenosis; ACT I, Asymptomatic Carotid Trial I; ICSS, International Carotid Stenting Study; CAVATAS-CEA, Carotid And Vertebral Artery Transluminal Angioplasty Studycarotid endarterectomy, TIA, transient ischemic attacks.
Minor stroke: a new stroke occurred for more than 24 hours; however, it did not meet the requirements of the major stroke.

The minor stroke also named nondisabling stroke. Minor stroke: The patients suffered an infarction due to the intracranial arterial occlusion with a neurological deficit. It must last at least $24 \mathrm{~h}$, and all patients was not disability (the MRS score was 2 or less).

The MRS was used to define the disabling stroke, it was at least 3 for 30 days or more, with an increase of at least 2 points than before the stroke. And the higher the MRS score, the more severe the disability.

Disabling stroke: MRS was used to define the disabling stroke, it was at least 3 for 30 days or more. Meanwhile, the remaining nonfatal strokes was defined as nondisabling.

Disabling stroke: MRS was used to define the disabling stroke, it was at least 3.

Non-disabling stroke: the patient had acute syndrome caused by focal disturbance of cerebral function lasting more than 24 hours, except fatal and disabling stroke.

TIA: patient had rapidly developing syndrome, which caused by focal disturbance of cerebral function lasting at least 24 hours due to cerebrovascular disease.

Any ipsilateral stroke: the cerebral infarction and/ or cerebral bleeding combined with persistent impairment of brain function (the MRS score was 3 or more). 
Table S3 Overview of included studies

\begin{tabular}{|c|c|c|c|c|c|c|c|}
\hline Trial & Country & Years & Type of Study & \multicolumn{2}{|c|}{ Participants (n) } & Use of EPDs & Carotid stenosis \\
\hline CREST & USA & 2010, 2011 & RCT & 1262 & 1240 & $97.9 \%$ & $\begin{array}{l}\text { Symptomatic and } \\
\text { asymptomatic }\end{array}$ \\
\hline ACT I & USA & 2016 & RCT & 1089 & 364 & $97.6 \%$ & Asymptomatic \\
\hline CAVATAS-CEA & UK & 2009 & RCT & 251 & 253 & NA & Symptomatic \\
\hline EVA 3S & USA & 2006, 2011 & RCT & 261 & 259 & $91.9 \%$ & Symptomatic \\
\hline Kentucky & USA & 2001 & RCT & 53 & 51 & None & Symptomatic \\
\hline
\end{tabular}

CEA, carotid endarterectomy; CAS, carotid artery stenting; EPDs, embolic-protection devices; NA, not available; CREST, carotid revascularization endarterectomy versus stenting trial; SPACE, Stent-Protected Angioplasty versus Carotid Endarterectomy; EVA3S,Endarterectomy versus Angioplasty in Patients with Symptomatic Severe Carotid Stenosis; ACT I, Asymptomatic Carotid Trial I; ICSS, International Carotid Stenting Study; CAVATAS-CEA, Carotid And Vertebral Artery Transluminal Angioplasty Study-carotid endarterectomy.

Table S4 Cochrane Collaboration's tool for quality assessment in trials comparing CAS to CEA

\begin{tabular}{|c|c|c|c|c|c|c|}
\hline Trials & $\begin{array}{l}\text { Sequence } \\
\text { generation }\end{array}$ & $\begin{array}{c}\text { Allocation } \\
\text { concealment }\end{array}$ & $\begin{array}{c}\text { Blinding of } \\
\text { outcome assessors }\end{array}$ & $\begin{array}{c}\text { Incomplete } \\
\text { outcome data }\end{array}$ & $\begin{array}{l}\text { Selective outcome } \\
\text { reporting }\end{array}$ & Others \\
\hline CREST & Low & Unclear & Low & Low & Low & Low \\
\hline Mannheim et al & Low & Unclear & Low & Low & Low & Low \\
\hline EVA $3 S$ & Low & Low & Low & Low & Low & Low \\
\hline Kentucky & Low & Unclear & Low & High & Low & Low \\
\hline Wallstent & Unclear & Unclear & Unclear & High & Low & Unclear \\
\hline
\end{tabular}

CEA, carotid endarterectomy; CAS, carotid artery stenting; CREST, carotid revascularization endarterectomy versus stenting trial; SPACE, Stent-Protected Angioplasty versus Carotid Endarterectomy; EVA-3S, Endarterectomy versus Angioplasty in Patients with Symptomatic Severe Carotid Stenosis; ACT I, Asymptomatic Carotid Trial I; ICSS, International Carotid Stenting Study; CAVATAS-CEA, Carotid And Vertebral Artery Transluminal Angioplasty Study-carotid endarterectomy. 
Table S5 Procedural characteristics and intervention of antiplatelet therapy

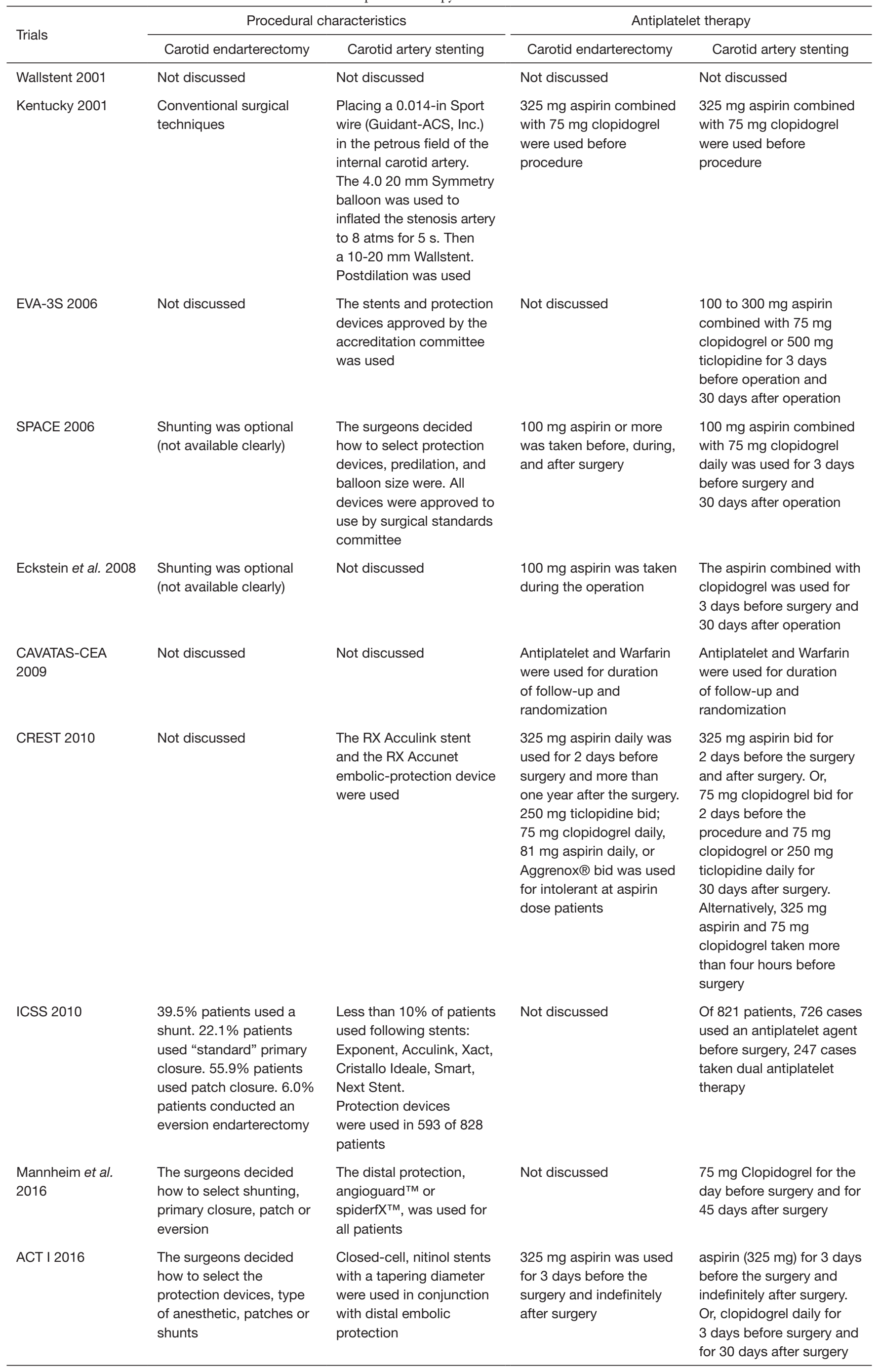


RR $(95 \% \mathrm{Cl}) \quad$ Weight

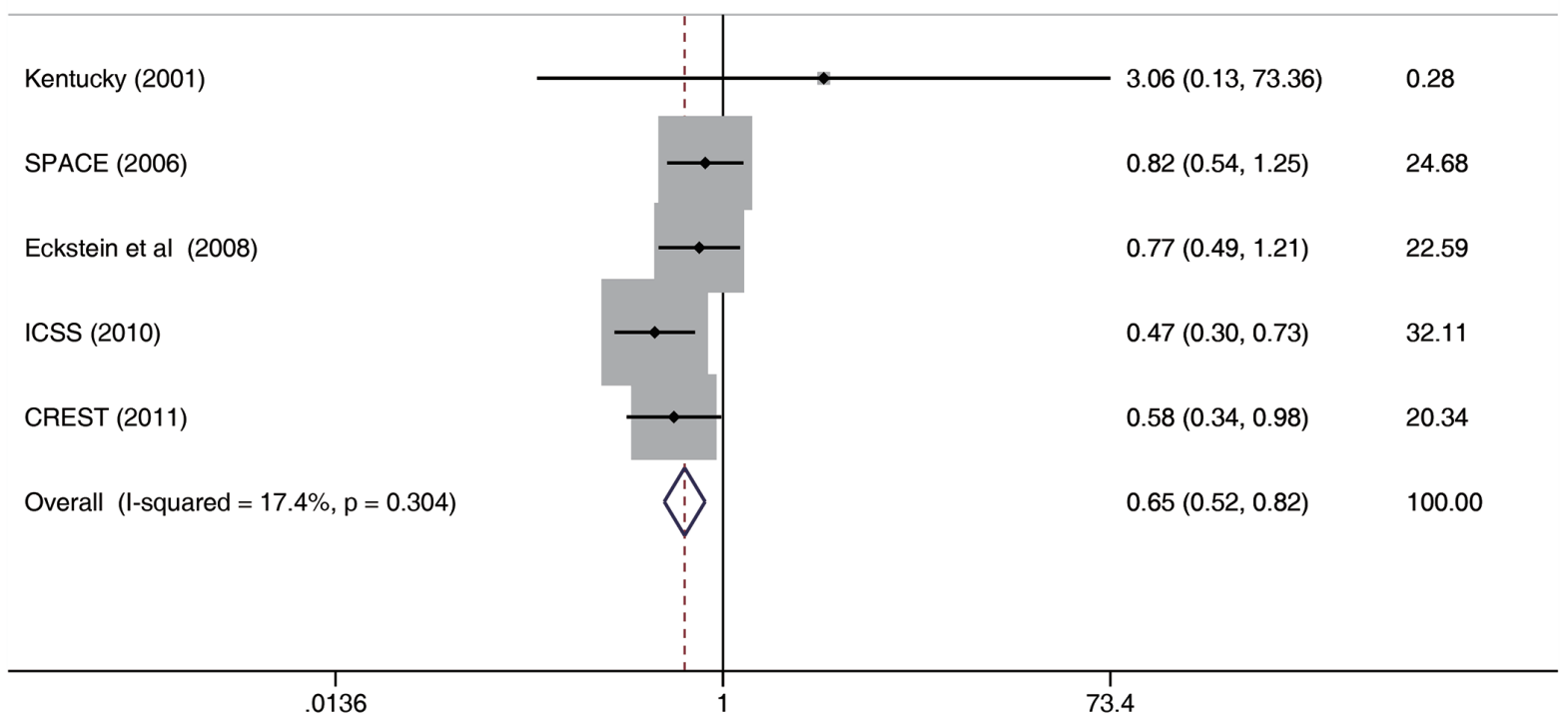

Figure S1 Forest plot of risk ratios (RR) of any stroke with carotid endarterectomy (CEA) vs. carotid artery stenting (CAS; control) for patients with symptomatic carotid stenosis.

Study

ID

RR $(95 \% \mathrm{Cl}) \quad$ Weight

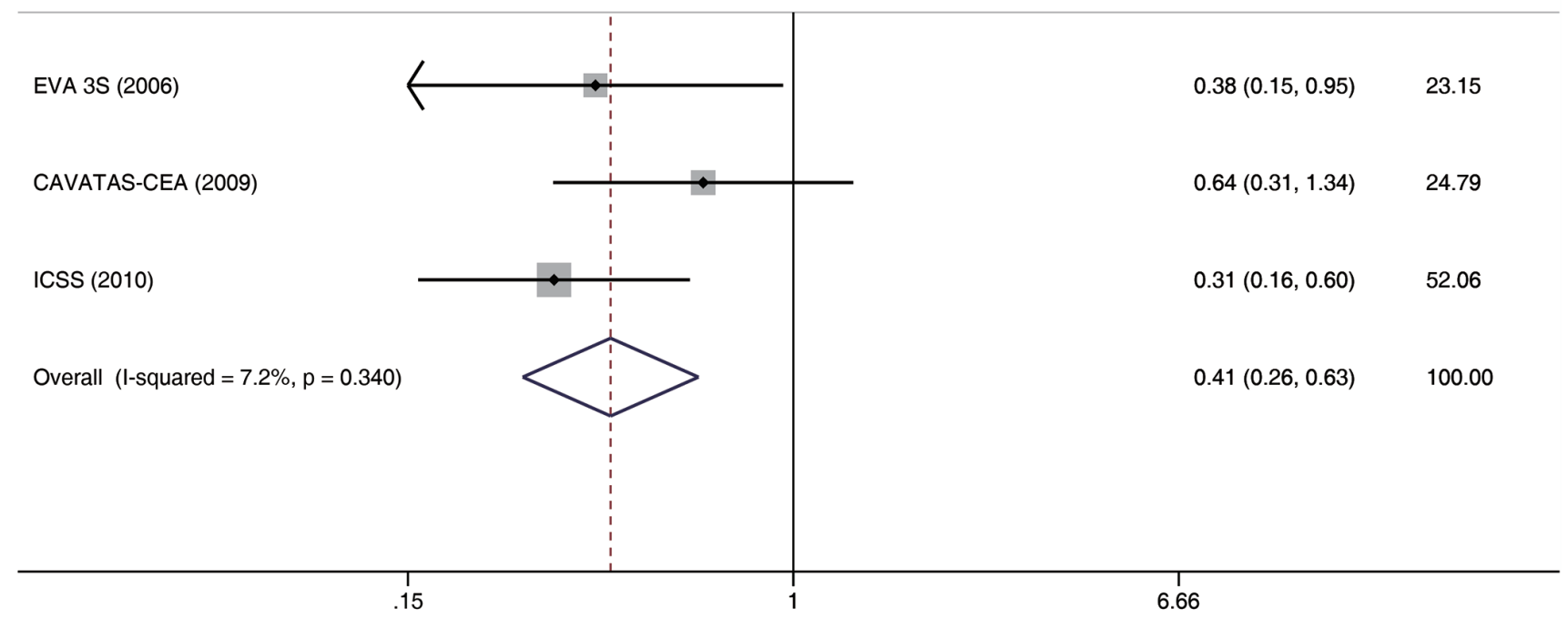

Figure S2 Forest plot of risk ratios (RR) of periprocedural non-disabling stroke with carotid endarterectomy (CEA) vs. carotid artery stenting (CAS; control) for patients with symptomatic carotid stenosis. 


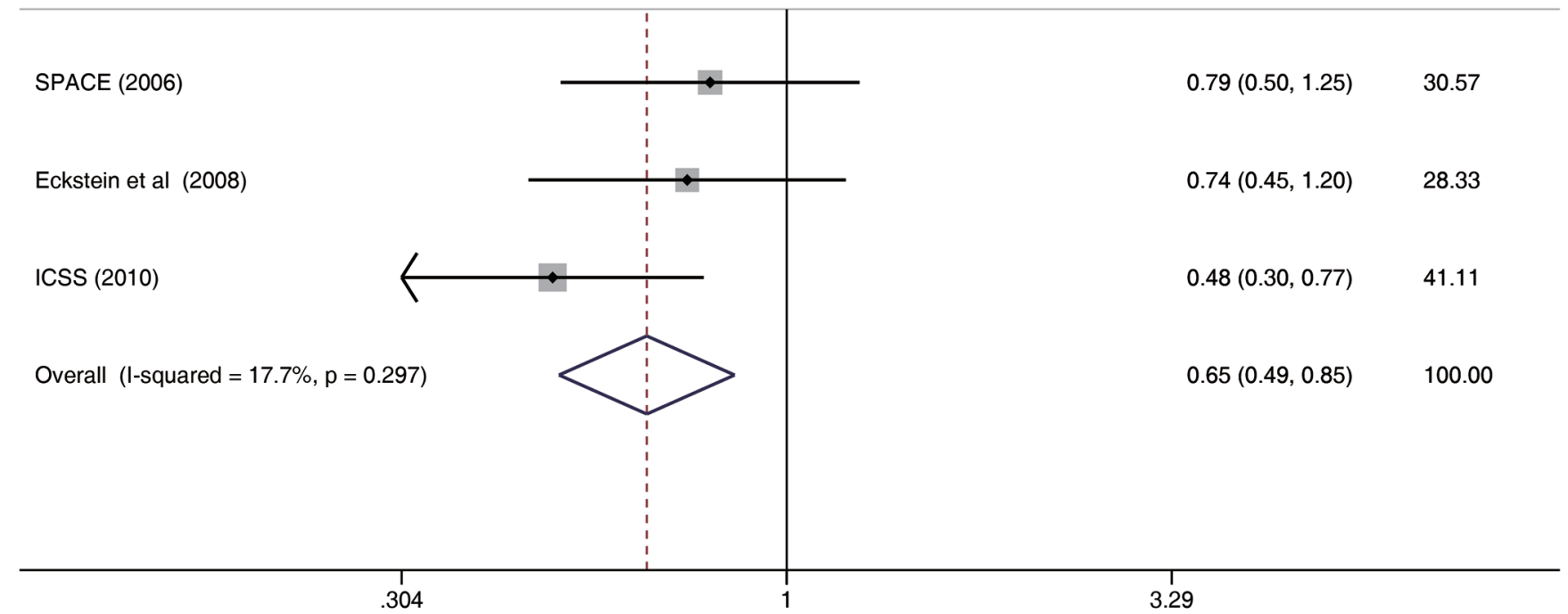

Figure S3 Forest plot of risk ratios (RR) of ipsilateral ischemic stroke with carotid endarterectomy (CEA) vs. carotid artery stenting (CAS; control) for patients with symptomatic carotid stenosis.

Study

ID

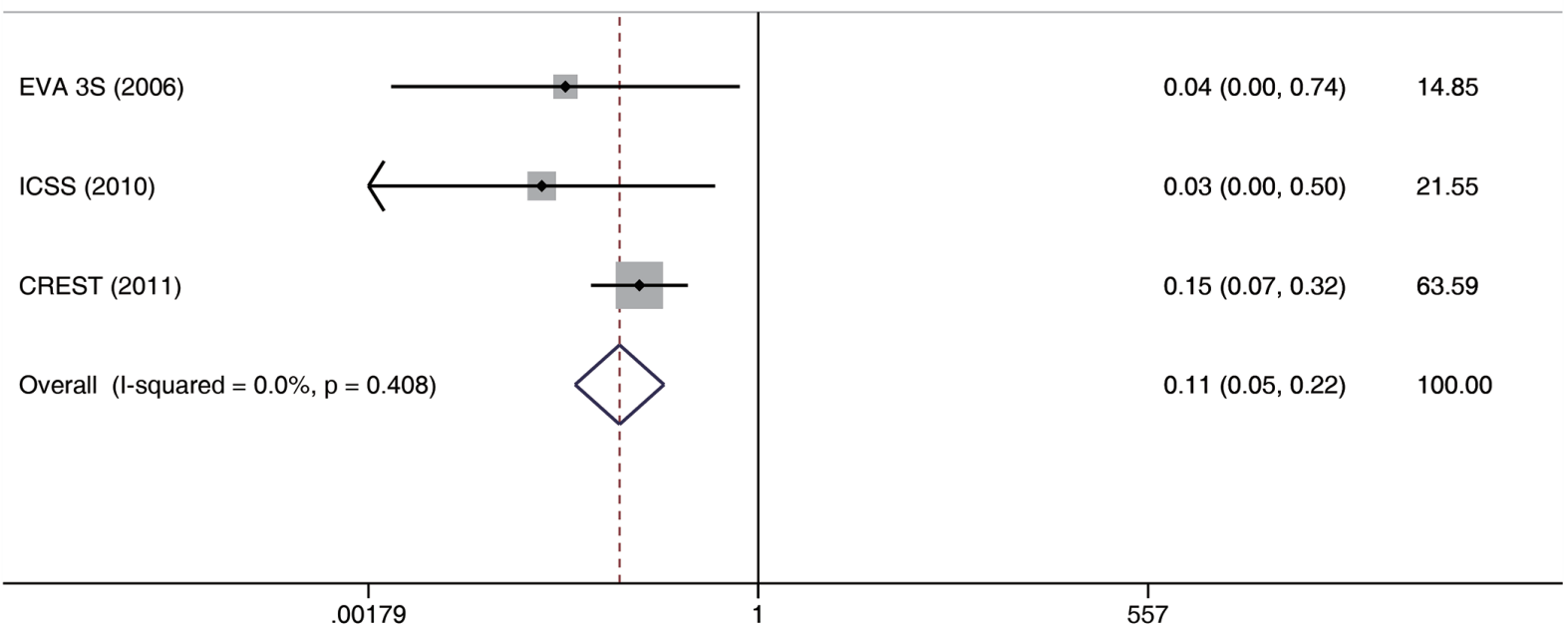

Figure S4 Forest plot of risk ratios (RR) of bradycardia or hypotension with carotid endarterectomy (CEA) vs. carotid artery stenting (CAS; control) for patients with symptomatic carotid stenosis. 
CREST (2011)

ACT I (2016)

Overall (I-squared $=0.0 \%, p=0.896$ )

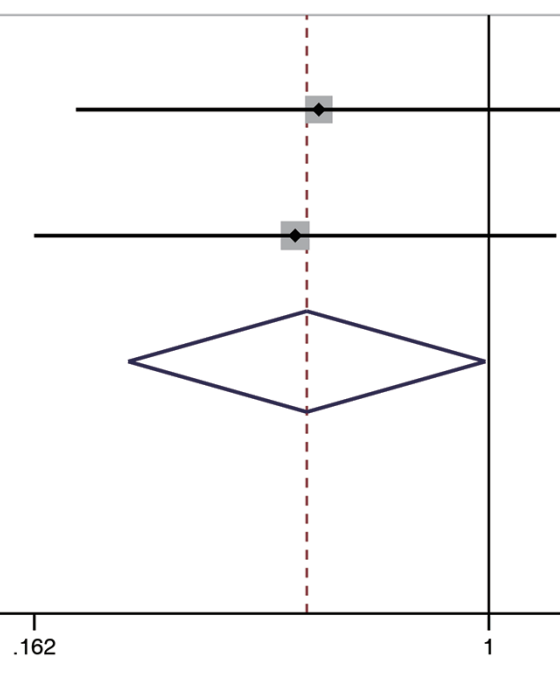

$0.51(0.19,1.34)$

47.80

$0.46(0.16,1.31)$

52.20

$0.48(0.24,0.99)$

100.00

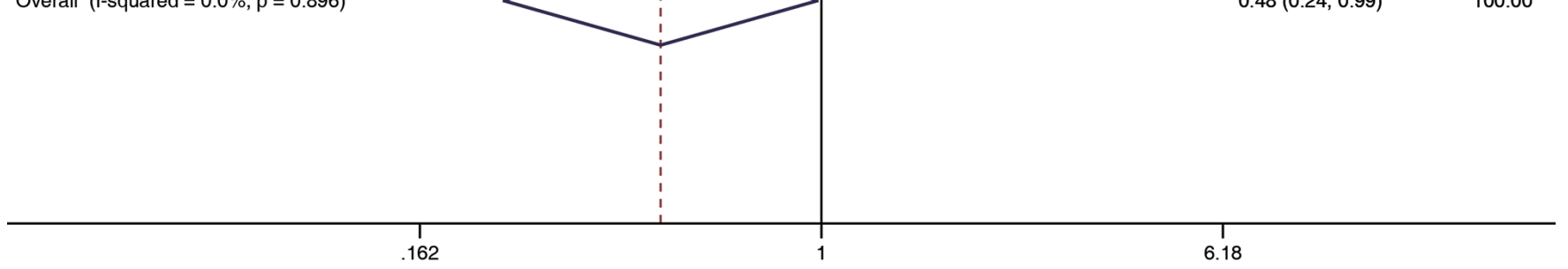

Figure S5 Forest plot of risk ratios (RR) of periprocedural minor stroke with carotid endarterectomy (CEA) vs. carotid artery stenting (CAS; control) for patients with asymptomatic carotid stenosis. 